ARTICLE

\title{
Observed increasing water constraint on vegetation growth over the last three decades
}

Wenzhe Jiao ${ }^{1}$, Lixin Wang (1) ${ }^{1 凶}$, William K. Smith², Qing Chang ${ }^{3}$, Honglang Wang ${ }^{4} \&$ Paolo D'Odorico (i) ${ }^{5}$

Despite the growing interest in predicting global and regional trends in vegetation productivity in response to a changing climate, changes in water constraint on vegetation productivity (i.e., water limitations on vegetation growth) remain poorly understood. Here we conduct a comprehensive evaluation of changes in water constraint on vegetation growth in the extratropical Northern Hemisphere between 1982 and 2015. We document a significant increase in vegetation water constraint over this period. Remarkably divergent trends were found with vegetation water deficit areas significantly expanding, and water surplus areas significantly shrinking. The increase in water constraints associated with water deficit was also consistent with a decreasing response time to water scarcity, suggesting a stronger susceptibility of vegetation to drought. We also observed shortened water surplus period for water surplus areas, suggesting a shortened exposure to water surplus associated with humid conditions. These observed changes were found to be attributable to trends in temperature, solar radiation, precipitation, and atmospheric $\mathrm{CO}_{2}$. Our findings highlight the need for a more explicit consideration of the influence of water constraints on regional and global vegetation under a warming climate.

\footnotetext{
${ }^{1}$ Department of Earth Sciences, Indiana University-Purdue University Indianapolis, Indianapolis, IN, USA. ${ }^{2}$ School of Natural Resources and the Environment, University of Arizona, Tucson, AZ, USA. ${ }^{3}$ O'Neill School of Public and Environmental Affairs, Indiana University, Bloomington, IN, USA. ${ }^{4}$ Department of Mathematical Sciences, Indiana University-Purdue University Indianapolis, Indianapolis, IN, USA. ${ }^{5}$ Department of Environmental Science Policy and Management, University of California, Berkeley, CA, USA.凶email: Ixwang@iupui.edu
} 
W ater is fundamental for plant growth, and vegetation response to water availability influences water, carbon, and energy exchanges between land and atmosphere ${ }^{1-4}$. Vegetation growth is expected to become more water constrained in a warmer climate because warming results in an increase in vapor pressure deficit and possible reductions in soil moisture ${ }^{5-8}$, while the observed global patterns of greening ${ }^{9-11}$ and increasing productivity $^{4,12}$ may also enhance vegetation water demand. In addition, higher temperature with more frequent extreme hot days $^{13,14}$, stronger radiation ${ }^{15}$, and land cover/land use changes ${ }^{4}$ may exacerbate water stress impacts ${ }^{12,16}$. Quantifying vegetation response to water availability at large spatial and temporal scales is challenging, as vegetation growth response to water availability is influenced by many interacting factors, including biome type, hydraulic strategy, water use efficiency, and location ${ }^{17-21}$. Simultaneously, a short-term decrease in rainfall may have both positive and negative effects on vegetation growth at different locations. For example, although water deficit negatively impacts many ecosystems, for ecosystems subjected to waterlogging or at high latitudes where temperature is a major limiting factor, shortterm precipitation deficiency may result in higher temperatures, leading to enhanced vegetation growth ${ }^{22-26}$.

Recent studies have documented vegetation response to water availability in terms of the negative impact of drought on vegetation productivity ${ }^{2,27,28}$, the timescale of vegetation response to drought ${ }^{18}$, and vegetation resilience and recovery from severe drought ${ }^{19,29}$. Yet, it remains unclear whether the impact of water availability on vegetation growth is changing in a warming climate. While various water deficit impacts have been documented, to our knowledge, a comprehensive global assessment of changes in long-term vegetation response to water constraints using the full satellite record is still missing. This knowledge gap prevents an adequate understanding of vegetation response to the expected intensification of drought frequency, severity, and duration ${ }^{30-35}$, and change in water availability ${ }^{36}$. In addition, recent studies have suggested that the strength of the terrestrial carbon sink might be shifting from an increasing to a decreasing trend $6,37,38$. This is likely related to changes of water constraints on vegetation growth.

In this study, we evaluated long-term trends of vegetation response to water availability over the last three decades in the extratropical Northern Hemisphere using a robust ensemble of water availability indices and multiple indicators of vegetation growth from 1982 to 2015 . We used satellite-derived normalized difference vegetation index (NDVI), enhanced vegetation index (EVI), vegetation optical depth (VOD), solar-induced chlorophyll fluorescence (SIF), and gross primary productivity (GPP) as proxies of vegetation growth; and self-calibrating Palmer drought severity index (scPDSI) and Standardized Precipitation Evapotranspiration Index (SPEI) aggregated over a range of time-scales as proxies of water availability. Both SPEI and scPDSI are meteorological water availability indices, and high to low values signify relatively wet to dry conditions in a given area as compared to its long-term average. Therefore, a year with low SPEI and scPDSI in a wet area may not necessarily cause vegetation water stress and may still be wetter than a year with high SPEI and scPDSI in a dry region ${ }^{39}$. The statistical relationship between water availability indices and vegetation growth has been widely applied to examine the response of vegetation growth to water availability ${ }^{18,40-42}$.

\section{Results and discussion}

Metrics to quantify the changes in water deficit, water surplus, and vegetation response time. Here we evaluated the relationship between:1) vegetation growth and SPEIs with time-scales ranging from 1- to 24-months; and 2) vegetation growth and
scPDSI over a fixed time-scale. SPEIs calculated over a specific time-scale represent the cumulative water balance over the total months of the specified time-period (e.g., SPEI03 represents the 3 -month cumulative water balance $)^{18,39}$. A significant positive correlation between NDVI and SPEI/scPDSI $(p<0.05)$ means that NDVI is increasing with wetting and decreasing with drying, suggesting that in the areas where this happens, vegetation growth is constrained by water scarcity. We term the area associated with significant positive correlation between NDVI and SPEI/scPDSI $(p<0.05)$ as "vegetation water deficit regions". In contrast, a significant negative correlation between NDVI and SPEI/scPDSI $(p<0.05)$ means that vegetation is less productive under wetter condition and more productive under drier than normal conditions, indicating a water surplus can limit vegetation growth as a result of waterlogging or of the fact that in some wetter years there might have been other factors such as temperature and solar radiation limiting productivity. We term the area associated with significant negative correlation between NDVI and SPEI/scPDSI $(p<0.05)$ as "vegetation water surplus regions". A non-significant relationship between NDVI and SPEI/ scPDSI $(p>0.05)$ indicates that vegetation growth is neither constrained by water scarcity nor by water surplus. To support the water deficit and water surplus classification based on positive and negative correlations between NDVI and SPEI/scPDSI, we showed that most of the areas with significant positive correlations between NDVI and SPEI/scPDSI $(p<0.05)$ were located in dryland regions (arid, semi-arid, and sub-humid regions) (Fig. 1), while most negative correlations were found in areas located outside drylands (or "non-dryland" regions, Fig. 1) (see "Methods" for dryland vs. non-dryland definitions by aridity index). Specifically, humid regions accounted for $95 \%$ and $96 \%$, respectively, of the significant negative $\mathrm{R}_{\mathrm{NDVI} \text {-SPEI03 (i.e., } r \text {-value }}$ between NDVI and 3-month time-scale SPEI, namely SPEI03; $p<0.05)$ and $\mathrm{R}_{\mathrm{NDVI} \text {-scPDSI }}$ (i.e., $r$-value between NDVI and scPDSI; $p<0.05$ ) (Fig. $1 c$ and d). By contrast, drylands accounted for $79 \%$ and $78 \%$ of the significant positive $\mathrm{R}_{\mathrm{NDVI}-\mathrm{SPEI03}}$ and $\mathrm{R}_{\text {NDVI-scPDSI }}$ (Fig. 1c and d). Moreover, the vast majority of semiarid and arid regions were associated with significant positive $\mathrm{R}_{\text {NDVI-SPEI03 }}$ ( $87 \%$ and $84 \%$, respectively) and $\mathrm{R}_{\text {NDVI-scPDSI }}(88 \%$ and $89 \%$, respectively) (Supplementary Fig. 1). This result is consistent with the expectation that most drylands are waterlimited, while only some humid regions, mainly characterized by peatlands, bogs, and other wetlands where waterlogging has been reported to limit productivity ${ }^{43-45}$, experience water surplus. A time lag typically exists between the onset of water scarcity and the emergence of observable consequences on vegetation ${ }^{18}$. Therefore, we defined the minimum vegetation response time to water stress ("response time" hereafter) as the minimum lag time between a drop in water availability (i.e., the onset of drier conditions) and the first observed impact on vegetation productivity. A shorter response time suggests a stronger susceptibility of vegetation to water stress. Similarly, we also defined the maximum water surplus period ("water surplus period" hereafter) as the maximum time between the start of drying and the last observed positive effect on vegetation growth. Shorter water surplus periods correspond to shorter periods in which vegetation growth experiences water surplus. The response time and water surplus period metrics allow us to quantify changes in the time of vegetation response to changes in water availability. We quantitatively attributed the observed changing responses of vegetation growth to water availability to multiple meteorological factors and atmospheric $\mathrm{CO}_{2}$ concentrations using attribution analysis.

Observed increasing water constraint on vegetation growth. Multiple lines of evidence show a markedly increasing water 


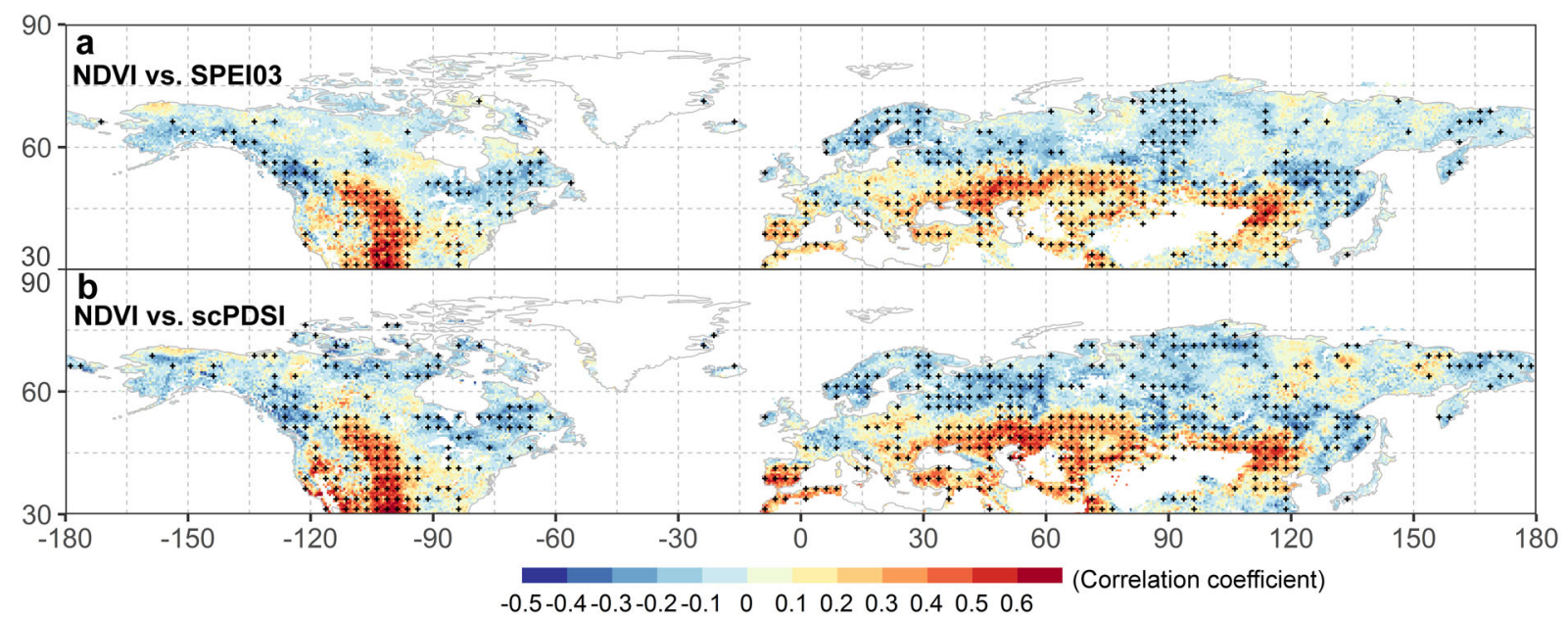

C NDVI vs. SPEI03

d NDVI vs. ScPDSI
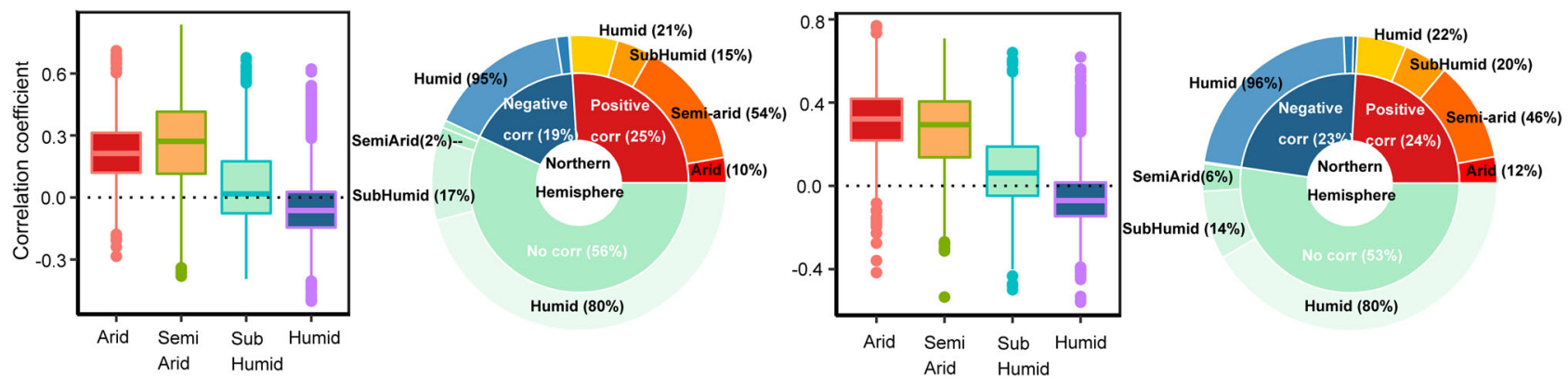

Fig. 1 Spatial distribution of the correlations between vegetation growth and water availability indices over the last three decades. $\mathbf{a}$, $\mathbf{b}$ Show the spatial distribution of correlation coefficients ( $\mathrm{R}_{\mathrm{NDVI}}$-SPEIO3 and $\mathrm{R}_{\mathrm{NDVI} \text {-scPDSI}}$ ) between normalized difference vegetation index (NDVI) anomaly and 3-month Standardized Precipitation-Evapotranspiration Index (SPEI03) and Palmer Drought Severity Index (scPDSI) for the entire study period. Black dots indicate

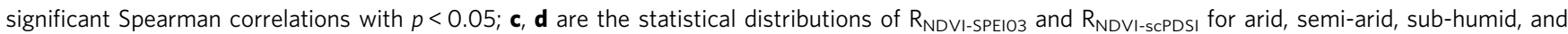
humid regions, respectively. The maximum and minimum extents of the colored boxes indicate the $25^{\text {th }}$ and $75^{\text {th }}$ percentiles and the whiskers represent the $5^{\text {th }}$ and $95^{\text {th }}$ percentiles, respectively.

constraint on extratropical Northern Hemisphere vegetation growth over the last three decades, as evidenced by the expansion of water-deficit regions and the shrinking of water surplus areas over the last three decades. The spatiotemporal correlations, $\mathrm{R}_{\mathrm{NDVI} \text {-SPEI03 }}$ and $\mathrm{R}_{\mathrm{NDVI} \text {-scPDSI}}$, indicated that most water deficit areas are located in temperate regions between $30^{\circ} \mathrm{N}$ and $50^{\circ} \mathrm{N}$, while most water surplus regions are located in high latitude boreal regions above $50^{\circ} \mathrm{N}$ (Fig. $2 \mathrm{a}$ and b). This pattern is consistent with the fact that high-latitude boreal regions are not water limited but energy limited, and short-term precipitation deficiency may result in higher solar radiation and temperature (and in some areas less waterlogging), leading to enhanced vegetation growth $^{25}$. We separately analyzed the trends for regions associated with water deficit and water surplus over the 1982-2015 period, and found remarkably divergent trends with a significant expansion of water deficit regions and a contraction of water surplus regions (Fig. $2 \mathrm{c}$ and $\mathrm{d}$ ). The results were consistent when using either $\mathrm{R}_{\mathrm{NDVI}-\mathrm{SPEI} 03}$ or $\mathrm{R}_{\mathrm{NDVI} \text {-scPDSI }}$ (Fig. $2 \mathrm{c}$ and $\mathrm{d}$ ).

To evaluate the robustness of our analysis, we used different moving windows, tested the impacts of long-term NDVI trends, tested the trends in sub-periods of the growing season, examined croplands separately, used different vegetation growth indicators, used water availability indicators at different time scales, and used a different water availability indicator (soil moisture) to reconduct our spatiotemporal analysis. In addition to results based on a 5-year moving window (Fig. 2), we used 10-year and 15-year moving windows to evaluate the trends. The spatiotemporal trends in $\mathrm{R}_{\text {NDVI-SPEI03 }}$ and $\mathrm{R}_{\mathrm{NDVI} \text {-scPDSI }}$ obtained using the 10-year and 15-year moving windows (Supplementary Fig. 2) showed great consistency with those from the 5-year moving window analysis (Fig. 2a-d). To examine whether the observed trends of productivity-moisture correlations were caused by the long-term NDVI trend, we detrended NDVI using both linear and nonlinear (moving average) methods and re-conducted our analyses on spatiotemporal trends of $\mathrm{R}_{\mathrm{NDVI}-\mathrm{SPEI} 03}$ and $\mathrm{R}_{\text {NDVI-scPDSI. }}$ The results (Supplementary Fig. 3) showed great consistency with those from the non-detrended analysis (Fig. 2a-d), indicating that the observed trends of productivitymoisture correlations were not caused by the long-term NDVI trend. To examine whether the shrinking of water surplus and the increasing water deficit trends occurred in different sub-periods of the growing season, we examined the spatiotemporal productivity-moisture relationship for three sub-periods: April-June, June-August, and August-October. The temporal trends of significant changes $(p<0.05)$ in percentage areas associated with water deficit and water surplus responses for these three sub-periods (Supplementary Fig. 4) showed that the shrinking of water surplus and expansion of water deficit occurred in most of the sub-periods, except for the shrinking water surplus, which was not significant in the April-June subperiod ( $p>0.05$ for Blue line trend in Supplementary Fig. $4 \mathrm{a}$ and d). It is likely because the increasing snowpack melting exacerbated water surplus in the spring. Interestingly, croplands showed increasing water constraint as well, except for irrigated croplands ${ }^{46}$ (which only account for around $11 \%$ of all the grid cells in the study area (Supplementary Fig. 5). In addition to 

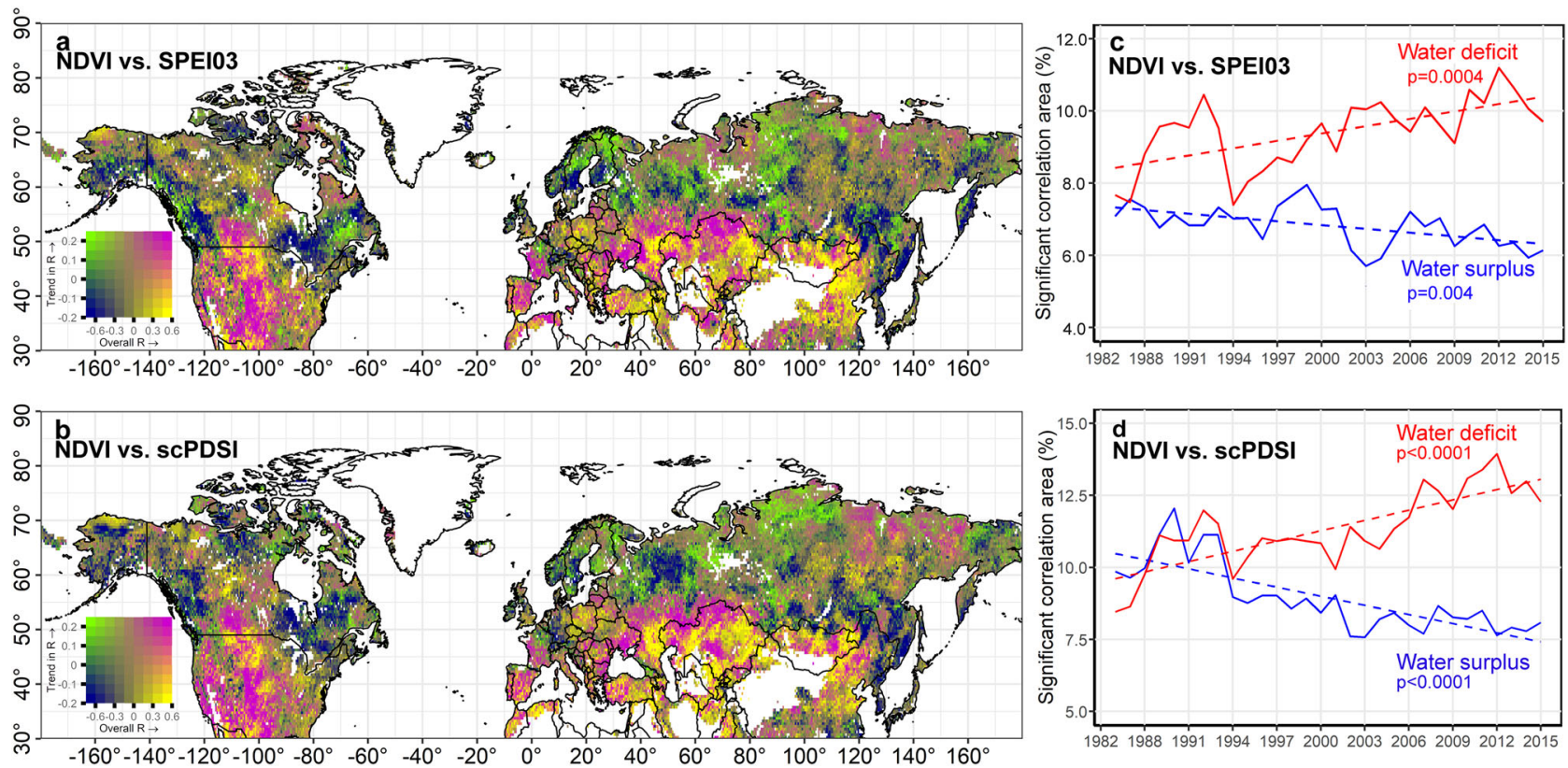

Fig. 2 Spatiotemporal distribution of the statistically significant correlations between vegetation growth and water availability indices over the last three decades. $\mathbf{a}$, $\mathbf{b}$ Show distribution of correlation coefficients ( $\mathrm{R}_{\mathrm{NDVI}-\mathrm{SPEIO3}}$ and $\mathrm{R}_{\mathrm{NDVI}-\mathrm{scPDSI}}$ ) between normalized difference vegetation index (NDVI) anomaly and 3-month Standardized Precipitation-Evapotranspiration Index (SPEIO3) and Palmer Drought Severity Index (scPDSI). The horizontal axis of the color legend is the correlation coefficient between NDVI anomaly and SPEIO3 (scPDSI) for the entire study period, the vertical axis of the color legend is the trend of correlation coefficient for the 30 five-year moving windows, no color indicates unvegetated regions. The chartreuse color stands for vegetation water surplus regions where water surplus has been decreasing; navy color indicates vegetation water surplus regions that have been experiencing an increase in water surplus; magenta color is used for water deficit regions that have been seeing an increase in water deficit; and regions colored in yellow are characterized by water deficit and a decrease in water deficit. c, $\mathbf{d}$ Show the temporal trends of significant changes in percentage areas associated with water deficit and water surplus responses using 5-year moving windows. Blue color stands for the water surplus response and red color for water deficit response. All the trends of water deficit and water surplus responses are significant in linear trend test and Mann-Kendall trend test ( $p<0.05)$. X-axes of (c, d) are binned using 5-year moving window to smooth out time series fluctuations and highlight the trends.

NDVI, we also used the VOD from 1988 to 2015, MODIS EVI, SIF, and GPP from 2000 to 2015 and GIMMS3g GPP from 1982 to $2011^{47}$ as vegetation growth indicators. Specifically, we evaluated to what extent the changes in the relationship between vegetation growth and water availability indices (SPEI03 and scPDSI) detected using NDVI were also consistently found with these other productivity indicators (i.e., VOD, SIF, EVI, and GPP). Our results showed comparable patterns of the changing correlations across all combinations of vegetation growth indicators and water availability indices. The trends of $\mathrm{R}_{\text {VOD-SPEI03 }}$ and $\mathrm{R}_{\text {VOD-scPDSI }}$ (1982-2011), $\mathrm{R}_{\text {SIF-SPEI03, }} \mathrm{R}_{\text {EVI-SPEI03, }}$ $\mathrm{R}_{\mathrm{GPP}-S P E I 03}, \mathrm{R}_{\mathrm{SIF}-\mathrm{scPDSI}}, \mathrm{R}_{\mathrm{EVI}-\mathrm{scPDSI}}$, and $\mathrm{R}_{\mathrm{GPP}-\text { scPDSI }}(2000-2015)$ were all comparable to the patterns of $\mathrm{R}_{\mathrm{NDVI}-\mathrm{SPEIO}}$ and $\mathrm{R}_{\text {NDVI-scPDSI }}$ (1988-2015) for the overlapping periods (Supplementary Fig. 6). To support the analysis based on 3-month timescale of SPEI (SPEI03) as water availability indicator, we recalculated the spatiotemporal vegetation-SPEI correlations based on SPEIs at all time-scales ranging from 1 to 24 months (SPEI01SPEI24) as water availability indicators. The significant negative and positive trends in the correlation between NDVI anomaly and SPEI $(\mathrm{p}<0.05)$ were confirmed at all time-scales ranging from 1 to 24 months (Supplementary Fig. 7). In addition to SPEI and scPDSI, we also used European Space Agency (ESA) Climate Change Initiative (CCI) program based soil moisture as water availability indicator to evaluate the robustness of

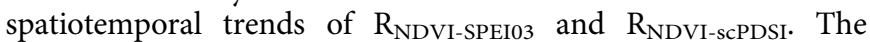
spatiotemporal relationship between vegetation growth and soil moisture $\left(\mathrm{R}_{\mathrm{NDVI}-\mathrm{SM}}\right)$ showed comparable patterns to the ones found using SPEI and scPDSI as water availability indicators (Supplementary Fig. 8).
To further support the water constraint analysis based on spatiotemporal vegetation-moisture correlations, we examined the temporal trend of NDVI anomalies under drought conditions (SPEI03 $<-1.28$ and scPDSI $<-1$ ) (see "Methods"). We found a significant decreasing trend $(p<0.05)$ in the drought-related NDVI z-score time series (i.e., increasing drought impact on vegetation growth) over the last three decades. The decreasing NDVI anomalies under drought (Supplementary Fig. 9) indicates an increasing drought impacts on vegetation growth, which further supports our finding that the vegetation water constraint is increasing over the last three decades.

Moreover, the mean correlation coefficient ( $r$-value) between NDVI anomaly and SPEI03 across all the grid cells in the Northern Hemisphere has increased steadily over the last three decades, switching from negative to positive for the whole extratropical Northern Hemisphere (Supplementary Fig. 10). This result indicates that the extratropical Northern Hemisphere vegetation growth is becoming increasingly constrained by water deficit, in agreement with our observations that significant positive correlations $(p<0.05)$ are typically associated with water deficit while negative correlations are typically associated with water surplus (Fig. 1). The increase in atmospheric $\mathrm{CO}_{2}$ levels is expected to lead to higher vegetation water use efficiency ${ }^{20}$, and increase plant water availability, especially in drylands ${ }^{48,49}$. As such, $\mathrm{CO}_{2}$ increase would induce a more negative correlation between NDVI anomaly and SPEI03 in water deficit regions. However, this study finds a steady increase of r-value between NDVI anomaly and SPEI03 in both water deficit and water surplus regions (Supplementary Fig. 11), indicating that $\mathrm{CO}_{2}$ induced water saving is not sufficient to counteract the increasing water constraint. 

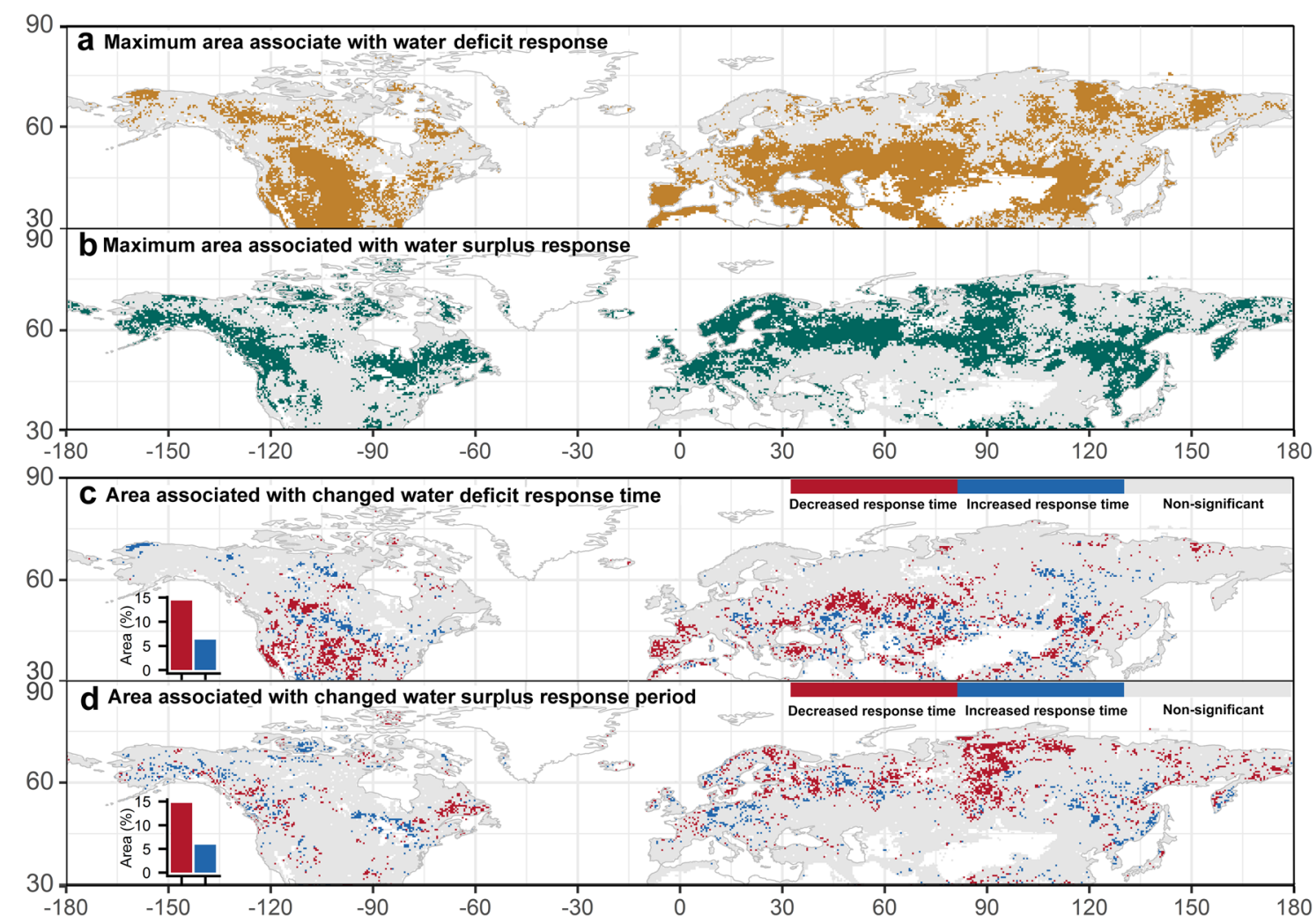

Fig. 3 Geographical distribution of maximum areas associated with water surplus and water deficit responses as well as the areas associated with changed response times to water surplus and water deficit over the last three decades. a Presents the maximum area composite of significant positive correlation (water deficit response) between normalized difference vegetation index (NDVI) anomaly and Standardized Precipitation-Evapotranspiration Index (SPEls) from 1- to 24-month time-scale (gold color); $\mathbf{b}$ the maximum area composite of significant negative correlation (water surplus response) between NDVI anomaly and SPEls from 1- to 24-month time-scale (green color); c area associated with change of response time to water deficit; $\mathbf{d}$ area associated with change of response time to water surplus response. The red and blue bars in (c, d) represent the areas of decreased and increased response time, respectively.

Further, a decreasing water deficit response time and shortened water surplus period were observed between the onset of water availability change and their observable impact on vegetation across the extratropical Northern Hemisphere. We evaluated the response time and water surplus period based on the statistically significant correlations between NDVI and SPEIs at different time-scales (see "Methods"). Over the study period, $44 \%$ of the Northern Hemisphere regions had NDVI positively correlated to at least one time-scale of SPEIs (Fig. 3a) and 38\% of the Northern Hemisphere regions had NDVI negatively correlated to at least one time-scale of SPEIs ranging from 1 to 24 months (Fig. 3b). This indicates that $44 \%$ of the Northern Hemisphere regions can be considered water deficit region and $38 \%$ of the Northern Hemisphere regions can be considered water surplus region for at least one month over the last 30 years. More importantly, our analysis indicates that about $14 \%$ of the Northern Hemisphere land area showed a significant decrease $(p<0.05)$ in response time, whereas $6 \%$ showed a significant increase $(p<0.05)$ in response time, resulting in an overall expansion of regions with decreased water deficit response time. In other words, there is an expansion of regions exhibiting a shorter water deficit response time, which corresponds to an increased vegetation susceptibility to stress induced by water scarcity (Fig. 3c). Similarly, about $6 \%$ of the Northern Hemisphere regions showed an increased water surplus period while $15 \%$ of the regions showed a decreased water surplus period, resulting in an overall expansion of regions with decreased water surplus period (i.e., shortened water surplus period) (Fig. 3d). Based on the previous results, a shorter water surplus duration is expected to favor plant productivity in water surplus regions. The shorter water deficit response time and shortened water surplus period across the Northern Hemisphere are also in support of the notion that vegetation growth in the Northern Hemisphere over the last three decades has become increasingly limited by water scarcity and not by surplus.

We finally evaluated the role of air temperature, precipitation, solar radiation, and atmospheric $\mathrm{CO}_{2}$ in mediating vegetation responses to water availability by carrying out an attribution analysis. We applied a partial correlation algorithm (see "Methods") to attribute the $\mathrm{R}_{\mathrm{NDVI}-\mathrm{SPEI} 03}$ and $\mathrm{R}_{\mathrm{NDVI}-\text { scPDSI }}$ to meteorological and atmospheric $\mathrm{CO}_{2}$ drivers (i.e., air temperature, precipitation, solar radiation, and atmospheric $\mathrm{CO}_{2}$ ). The partial correlation of each factor was calculated for each grid cell (Supplementary Fig. 12). The factor associated with the largest absolute value of partial correlation was identified as the dominant factor to the $\mathrm{R}_{\mathrm{NDVI}-\mathrm{SPEIO}}$ and $\mathrm{R}_{\mathrm{NDVI}-\mathrm{scPDSI}}$ in that grid cell (Fig. $4 \mathrm{a}$ and b). The area associated with each dominant factor was then calculated for the water deficit and the water surplus regions separately (Fig. $4 \mathrm{c}$ and $\mathrm{d}$ ). The area fraction associated with each dominant factor was calculated for the water deficit and the water surplus regions, respectively (i.e., the dotted blue and red color regions as identified in Fig. 1a and b). While the partial correlation analysis revealed that there was no single driver responsible for the increasing vegetation water constraint, $\mathrm{R}_{\mathrm{NDVI}-S P E I 03}$ and $\mathrm{R}_{\mathrm{NDVI} \text {-scPDSI }}$ were attributable to precipitation and radiation for a relatively large portion of both the water deficit and water surplus regions (Fig. $4 c$ and d). Specifically, we found that in water surplus regions (i.e., the dotted 

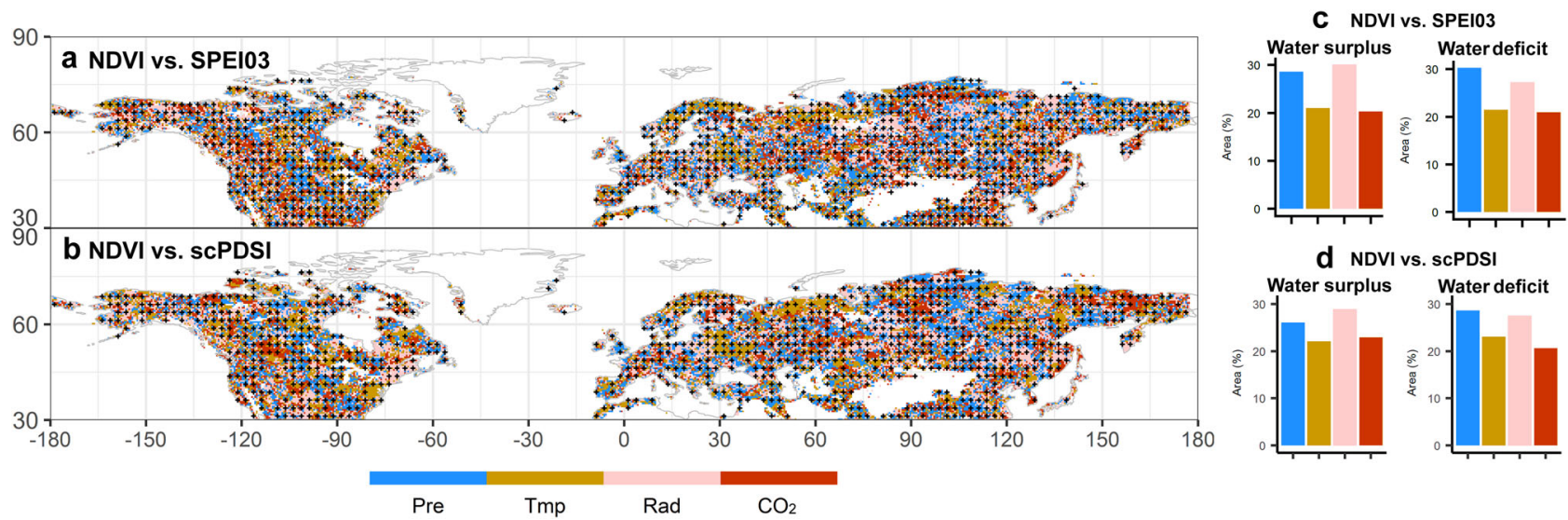

Fig. 4 Attribution of meteorological factors and atmospheric $\mathrm{CO}_{2}$ to the correlations between normalized difference vegetation index (NDVI) anomaly and water availability indices over the last three decades. $\mathbf{a}, \mathbf{b}$ are the spatial distributions of the dominant factor influencing $\mathrm{R}_{\mathrm{NDVI}}$-SPEIO3 ${ }$ and $\mathrm{R}_{\mathrm{NDVI}}$-scPDSI, respectively. The dots show the regions that $\mathrm{R}_{\mathrm{NDVI}-S P E I 03}$ or $\mathrm{R}_{\mathrm{NDVI} \text {-scPDSI }}$ variations are significantly explained by precipitation, radiation, temperature, and atmospheric $\mathrm{CO}_{2}$. c, d The percentage areas where the water deficit and water surplus responses can be explained by one of the four dominant factors (i.e., precipitation, temperature, radiation, and $\mathrm{CO}_{2}$ ). Pre: precipitation, Rad: radiation, Tmp: temperature, $\mathrm{CO}_{2}$ : atmospheric $\mathrm{CO}_{2}$.

blue regions in Fig. 1a), $29 \%$ and $30 \%$ of $\mathrm{R}_{\text {NDVI-SPEI03 was }}$ attributable to precipitation and radiation, respectively (Fig. 4c). Similarly, in water deficit regions (i.e., the dotted red color regions in Fig. 1a), $30 \%$ and $27 \%$ of $\mathrm{R}_{\mathrm{NDVI} \text {-SPEI03 }}$ was attributable to precipitation and radiation, respectively (Fig. $4 \mathrm{c}$ ). The areas where $\mathrm{R}_{\mathrm{NDVI} \text {-scPDSI }}$ was explained by precipitation and radiation were consistent with those for $\mathrm{R}_{\mathrm{NDVI}}$-SPEI03 (Fig. $4 \mathrm{c}$ and $\mathrm{d}$ ). It was also found that in water surplus regions $21 \%$ and $20 \%$ of the $\mathrm{R}_{\mathrm{NDVI}}$ SPEI03, and $22 \%$ and $22 \%$ of the $\mathrm{R}_{\mathrm{NDVI}-\text { scPDSI }}$ were attributable to temperature and $\mathrm{CO}_{2}$, respectively (Fig. $4 \mathrm{c}$ and d). In water

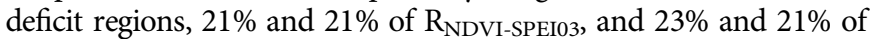
$\mathrm{R}_{\mathrm{NDVI} \text {-scPDSI }}$ were attributable to temperature and $\mathrm{CO}_{2}$, respectively (Fig. $4 \mathrm{c}$ and $\mathrm{d}$ ). The most likely explanation that the observed productivity-moisture correlations were attributable to a greater extent to precipitation and radiation in both water deficit and water surplus regions is that these two meteorological variables capture water and energy constraints and are closely related at large spatial scales. For example, most of the water deficit regions (e.g., the regions in the south and west of the United States) showed decreasing precipitation and slightly increasing radiation (Supplementary Fig. 13a and b); whereas water surplus regions (e.g., southeast United States and multiple regions in Russia) showed increased shortwave radiation and to a lesser extent decreasing precipitation (Supplementary Fig. 13a and b). The fact that in some regions temperature is the major attribution factor for the observed correlation patterns is likely due to the increasing frequency in extreme hot days ${ }^{14}$, which in turn are associated with higher atmospheric water demand ${ }^{6}$. In high-latitude water surplus regions, plants affected by cell damage caused by more frequent extreme hot days may consistently experience reduced growth even in drier periods. In water deficit regions higher temperature and solar radiation increase evapotranspiration/potential evapotranspiration making the soils drier, exacerbating vegetation water stress exposure ${ }^{15,50}$. For the regions where $\mathrm{R}_{\mathrm{NDVI} \text {-SPEI03 }}$ and $\mathrm{R}_{\mathrm{NDVI} \text {-scPDSI }}$ are dominated by $\mathrm{CO}_{2}$, we may be capturing an increase in vegetation water use efficiency under increasing $\mathrm{CO}_{2}$ concentrations ${ }^{20}$. To evaluate the robustness of our attribution analysis, we also used a "relaimpo" 51 relative importance analysis to quantify the relative contributions of each factor. Results from the relative importance analysis were comparable to those from the partial correlation analysis (Supplementary Fig. 14).

These results, which appear to be robust with respect to possible trends induced by sensor aging/shift and other sources of uncertainty such as drought legacy effect and grid cell contaminations (see "Methods"), provide multiple lines of evidence for an overall increase of water constraints on extratropical Northern Hemisphere vegetation growth over the last 30 years. With future warming, regions experiencing water constraints will likely increase, resulting in a reduction of carbon uptake across the extratropical Northern Hemisphere, thus potentially amplifying the global carbon-climate feedback. Consistent with previous studies ${ }^{23,37,38}$, we found that the increasing vegetation water constraints are associated with increasing negative drought impacts hidden in the overall greening trends, with plants becoming increasingly sensitive to drought. With the projected increasing frequency and severity of drought events ${ }^{31}$, the increasing water constraint is likely to be the one major factor causing the strength of the terrestrial carbon sink to shift from an increasing to a decreasing trend under climate change. More importantly, even without drought, the increasing vegetation water constraint could be one of the main factors counteracting the fertilization effect from $\mathrm{CO}_{2}$ and nitrogen on vegetation growth, leading to a decreasing trend of terrestrial carbon sink under the warming climate.

\section{Methods}

Satellite observation data. The third-generation biweekly Advanced Very High Resolution Radiometer (AVHRR) NDVI (GIMMS-NDVI3g, available at https:// ecocast.arc.nasa.gov/data/pub/gimms/3g.v0) data were used in this study as a proxy for vegetation growth between 1982 and 2015. The study period of 1982-2015 was selected to balance the data availability for vegetation growth and water availability indicators. For example, the Standardized Precipitation-Evapotranspiration Index (SPEI) dataset is currently available only to the year 2015. The GIMMS-NDVI3g data have corrections for sensor degradation, cloud cover, inter-sensor differences, solar zenith angle, viewing angle effects, and volcanic aerosols, making them widely used to study the vegetation dynamics under warming climate ${ }^{4,13}$. Ku-band vegetation optical depth (VOD) was selected from 1988 to 2015. The maximum value composite method was applied to composite daily VOD into monthly datasets, and the cubic resampling method was used to aggregate $0.05^{\circ}$ spatial resolution into $0.5^{\circ}$ to match the spatial resolution from climate datasets. Daily $\mathrm{Ku}-$ band VOD data ${ }^{52}$ were obtained from https://zenodo.org/record/2575599 \#.XzivuMBKipp. Moderate Resolution Imaging Spectroradiometer (MODIS) based enhanced vegetation index (EVI) and gross primary production (GPP), as well as solar-induced chlorophyll fluorescence (SIF) data derived from discrete the Orbiting Carbon Observatory-2 (OCO-2) SIF and MODIS observations (GOSIF ${ }^{53}$, were selected from 2000 to 2015 as complementary proxies for vegetation growth and were used here for evaluating the robustness of the observed trends based on NDVI. GOSIF uses a combination of the OCO-2 SIF with MODIS version 6 data, which alleviated the issue of sensor degradation. Monthly GOSIF data were obtained from http://data.globalecology.unh.edu/data/GOSIF/. Version 6 of EVI (MOD13A3) and GPP (MOD17A2H) were aggregated to $0.5^{\circ} \times 0.5^{\circ}$ to match the resolution of meteorological data. In addition, GPP data from 1982 to 2011 based on MODIS GPP algorithm driven by GIMMS fraction vegetation absorbed 
photosynthetically active radiation (fPAR) and leaf area index (LAI) data ${ }^{47}$ were used to evaluate the robustness of the observed trends using EVI and GPP and to make up for the absence of MODIS-based vegetation growth data before 2000. The maximum value composite method and the cubic resampling method were used to composite 8-day and bi-weekly data into monthly with $0.5^{\circ}$ spatial resolution for the remote sensing-based data to match the spatial and temporal resolution of water availability indices and climate data ${ }^{13}$. The detailed evaluation of MODIS algorithm based GIMMS-GPP from 1982 to 2011 could be found in Smith et al. ${ }^{47}$.

\section{Gridded water availability indices. Standardized Precipitation-} Evapotranspiration Index (SPEI) and self-calibrating Palmer Drought Severity Index (scPDSI) are widely used as water availability indices to quantify water deficit onset, duration, magnitude, and spatial extent $t^{5,19,29,34}$. The monthly scPDSI, calculated based on balance model of precipitation, temperature, and potential evapotranspiration (PET) ${ }^{54,55}$ were provided by the Research Data Archive at the National Center for Atmospheric Research (NCAR). The monthly scPDSI was aggregated to $0.5^{\circ} \times 0.5^{\circ}$ using cubic resampling method. Monthly SPEI was calculated based on historical probability distribution of precipitation minus potential evapotranspiration (PET) ${ }^{39}$. Both SPEI and scPDSI used Penman-Monteith method to calculate PET. The main difference between SPEI and scPDSI is that SPEI provides multiple time-scales and scPDSI is with fixed time-scale ${ }^{39}$. The $0.5^{\circ}$ with 1-24 time-scales of SPEI were selected in this study to characterize the cumulative water balance conditions from the previous $1-24$ months $\mathrm{s}^{39}$.

1-24 month time-scale of SPEIs were obtained from http://digital.csic.es/handle/ 10261/153475, and scPDSI from 1982 to 2015 are available at https://rda.ucar.edu/ datasets/ds299.0/. Aridity index (AI) is defined as the ratio of mean annual rainfall to mean annual potential evapotranspiration. Aridity index was used identify arid $(\mathrm{AI}<0.2)$, semi-arid $(0.2 \leq \mathrm{AI} \leq 0.5)$, sub-humid $(0.5 \leq \mathrm{AI} \leq 0.65)$, and humid $(\mathrm{AI} \geq 0.65)$ regions ${ }^{56,57}$. The spatial AI dataset was obtained from https://cgiarcsi. community/data/global-aridity-and-pet-database/. The 30 arc seconds spatial resolution was aggregated to $0.5^{\circ} \times 0.5^{\circ}$ using cubic resampling method to match the resolution of water availability indices and meteorological data. In addition to SPEI and scPDSI, Essential Climate Variable (ESA) soil moisture data (version $05.2)^{58-60}$ (www.esa-soilmoisture-cci.org/) was used as an additional water availability indicator to evaluate the water constraint and water surplus trends. The daily ESA soil moisture data were aggregated into monthly using monthly mean values.

Forcing datasets. Monthly meteorological (including air temperature, precipitation, incoming shortwave radiation) and atmospheric $\mathrm{CO}_{2}$ data with spatial resolution of $0.5^{\circ} \times 0.5^{\circ}$ were used to quantify the attributions of the observed relationships between vegetation growth and water availability indices from 1982 to 2015. Monthly air temperature and precipitation data with a spatial resolution of $0.5^{\circ} \times 0.5^{\circ}$ were obtained from Climate Research Unit (CRU) at the University of East Anglia (CRU TS 3.23) ${ }^{61}$. The shortwave radiation data was obtained from the Terrestrial Hydrology Research Group at Princeton University ${ }^{62}$ (http://hydrology. princeton.edu/data/pgf/v2/0.5deg/monthly/).

Trend analyses of vegetation and water availability relationships. To examine the general change of vegetation growth responses to water availability, we conducted the analyses of the spatiotemporal relationship between the growing season (April to October) NDVI anomaly and the two water availability indices (SPEI03 and scPDSI) for each grid cell over the Northern Hemisphere from 1982 to 2015. SPEI03 represents 3-month Standardized Precipitation-Evapotranspiration Index. NDVI anomaly was used to remove the effect of seasonality, and we calculated the NDVI anomaly based on $z$-score of NDVI using the formula of $A_{j, i}=\left(\frac{N D V_{j, i}-N \overline{D V V I}}{\sigma}\right)$, where $A_{j, i}$ denotes NDVI anomaly for the month $j$ in year $i, N \overline{D V} I_{j}$ denotes the averaged NDVI of month $j$ over 1982-2015; $\sigma$ stands for the standard deviation of NDVI for month $j$ over 1982-2015. Spearman rank correlation coefficients $(r$ values) between NDVI anomaly and the two water availability indices ( $\mathrm{R}_{\text {NDVI-SPEI }}$ and $\mathrm{R}_{\mathrm{NDVI}-\text {-scPDSI }}$ ) were used to represent the NDVI and SPEI (or scPDSI) relationship. Grid cells with significant positive and negative correlations $(p<0.05)$ between vegetation indicators and water availability indices were defined as grid cells associated with water deficit and water surplus, respectively. The ratio between the sum of all the grid cells associated with water deficit and total grid cells was defined as the percentage area associated with water deficit across the Northern Hemisphere each year. The same approach was used to calculate the percentage area associated with water surplus across the Northern Hemisphere each year. Given that the time-scales at which different biome types respond to water availability may differ noticeably ${ }^{19}$, in addition to SPEI03, we further estimated the correlations between NDVI anomaly and SPEI separately for 1 to 24 month time-scales. In addition to SPEI and scPDSI, ESA soil moisture data was used as one additional water availability indicator and spatiotemporal relationships between the growing season (April to October) NDVI anomaly and ESA soil moisture were also conducted.

To quantify the spatiotemporal dynamics of water deficit and water surplus regions over the last three decades, the trends of correlation coefficients between vegetation growth indicators and water availability indices of 5-year moving window for each grid cell were analyzed using linear and Mann-Kendall trend test (e.g., Fig. 2a and b). We used 5-year moving window in our trends analysis in this study to smooth out time series fluctuations and highlight trends. Ten-year and 15year moving window also used in our study to evaluate the robustness of the 5-year moving window trend analysis. A longer the moving window resulted in less total time series points and a reduction in fluctuations from time point to time point, which helped to highlight any potential long-term trend. We focus our presentation of the results on the 5-year moving window analysis since it maximized the number of time series points while still consistently highlighting any emergent long-term trends in the data. To analyze the changes in areas associated with water deficit/water surplus across the Northern Hemisphere, the trend of percentage area associated with water deficit/water surplus was analyzed with a 5-year moving window using linear and Mann-Kendall trend analysis (e.g., Fig. $2 \mathrm{c}$ and d). To evaluate the robustness of the relationships between NDVI and the two water availability indices, we used the same method to analyze the relationships between VOD, SIF, EVI, and GPP and the two water availability indices across the Northern Hemisphere (e.g., Supplementary Fig. 6). Temporal consistency analysis based on multiple independent satellite observations imply that the observed changes in vegetation water deficit and water surplus responses were not caused by inadequate corrections of sensors for sensor aging and sensor shift $^{63}$. To examine whether the trends of observed productivity-moisture correlations were caused by long-term NVDI trends, we repeated the same analyses of $\mathrm{R}_{\mathrm{NDVI}-\mathrm{SPEI} 03}$ and $\mathrm{R}_{\mathrm{NDVI}}$-scPDSI on detrended NDVI time series, using both linear and nonlinear detrending methods. For the linear detrending method, we first tested the linear trend significance for each pixel from 1982 to 2015 and then removed the slope of any significant increasing or decreasing trend $(p<0.05)$ in each pixel. For non-linear detrend method, we extracted the non-linear trend using interannual moving average method. The non-linear trend was extracted using the decompose function in R. We also find that the drought legacy effect (i.e., reduced vegetation growth and incomplete recovery after extreme drought events) ${ }^{64,65}$ is unlikely to play a dominant role in influencing the trend of vegetation response to water availability since we found similar trends in NDVI responses to 1 month SPEI to 24 months SPEI (Supplementary Fig. 7). Nevertheless, multiple uncertainties may affect the understanding of the water constraint changes on vegetation in our study. These may include uncertainties of water availability and vegetation indices at high latitudes, uncertainties of vegetation growth indicators due to snow and/or cloud contamination, and uncertainties due to unaccounted for insect and fire disturbances ${ }^{66}$. However, because we found multiple lines of evidence of increasing vegetation water constraint, we do not expect these uncertainties to affect our key findings.

To further test the vegetation water constraint trends in addition to spatiotemporal vegetation-moisture correlations, we examined the temporal trend of NDVI anomalies under drought. To examine the drought impacts on vegetation while minimize impacts from other confounding factors such as $\mathrm{CO}_{2}$ fertilization and lengthening of the growing season, we used both linear and nonlinear detrending methods for each grid cell. Linear detrending consisted in removing the slope of monthly NDVI for five years intervals between 1982 and 2015. Nonlinear detrending consisted in removing the moving average of interannual trend. The detrended NDVI anomaly was then calculated based on the de-trended z-score of growing-season (April-October) NDVI. We then analyzed the change of detrended NDVI anomaly under drought conditions. We extracted all the grid cells of de-trended NDVI anomaly that are under drought conditions indicated by 3 month time-scale SPEI (SPEI03) and scPDSI from 1982 to 2015. scPDSI $<-1$ and SPEI $03<-1.28$ were defined as drought conditions ${ }^{2}$.

Analysis of vegetation response time to water availability. It has been well documented that climate conditions accumulatively impact vegetation growth and plants have lagged response to climate over a period of time ${ }^{67-69}$. The concept of drought time-scale of $n$ months indicates $n$ months of cumulative water balance $39,70,71$ and significant relationship between NDVI and $n$-month time scale SPEI $(p<0.05)$ indicates the existence of a significant relationship between a $n$ month cumulative water balance indicator and vegetation growth $(p<0.05)^{18}$. Accordingly, we defined the minimum SPEI time-scale (in the 1-24 month range) associated with significant positive correlation to NDVI anomaly $(p<0.05)$ as the minimum water deficit response time for each grid cell. Similarly, we defined the maximum SPEI time-scale associated with significant negative correlation to NDVI anomaly as the maximum water surplus period $(p<0.05)$ for each grid cell. We first extracted the maximum area associated with significant vegetation water deficit by accounting for all the grid cells with significant positive correlation between NDVI anomaly and SPEIs $(p<0.05)$ in the subsequent 1 - to $24-$ months. A given grid cell was classified as having vegetation constrained by water scarcity when at least one of the subsequent 1-24 month SPEIs exhibited a significant positive correlation with NDVI (low SPEI with low NDVI, $p<0.05$ ). If in a given grid cell SPEIs had significant positive correlation with NDVI $(p<0.05)$ with more than one time lags, the minimum time-lag associated with significant positive correlation was used. Similarly, we extracted the largest areas associated with significant water surplus $(p<0.05)$ by accounting for all the grid cells with significant negative correlation between NDVI anomaly and SPEIs $(p<0.05)$ in the subsequent 1 - to 24 - months. A given grid cell was classified as having vegetation affected by water surplus when at least one time-lag exhibited a significant negative correlation between SPEI and subsequent NDVI (low SPEI with high NDVI, $p<0.05$ ). If more than one time-lag 
exhibited a significant negative correlation between SPEIs and NDVI $(p<0.05)$ for a given grid cell, the maximum time-lag associated with a significant negative correlation $(p<0.05)$ was used. We then analyzed the trends of minimum water deficit response time and maximum water surplus period separately for each grid cell based on a 5-year moving window. The linear trend test was applied for each grid cell over the period of $1982-2015$ to examine the significance $(p<0.05)$ of trend for vegetation response time to water availability. Since we separately examined the change of water deficit and water surplus regions, a grid with both positive and negative correlation did not affect our analysis.

Attribution analysis. The contributions of meteorological factors (mean annual air temperature, precipitation, and shortwave radiation), and atmospheric $\mathrm{CO}_{2}$ to the observed trends of vegetation growth and water availability relationships were assessed using partial regression models. We fitted full models for $r$-values of the correlations between NDVI anomaly and water availability indices as a function of mean growing season air temperature, mean growing season precipitation, mean growing season shortwave radiation, and atmospheric $\mathrm{CO}_{2}$ of each 5-year moving window for each grid cell. We used the $p$-value $(p<0.05)$ of multivariate regression models to examine whether these factors are statistically contributed to the changes of correlations between NDVI anomaly and water availability indices $\left(\mathrm{R}_{\text {NDVI-SPEI }}\right.$ and $\mathrm{R}_{\mathrm{NDVI}-\mathrm{scPDSI}}$ ). To determine the most important contributor of the $\mathrm{R}_{\mathrm{NDVI}-\mathrm{SPEI}}$ and $\mathrm{R}_{\text {NDVI-scPDSI }}$ temporal dynamics, we ranked these factors based on the absolute value of partial correlation coefficients of each factor. This method was applied for every grid cell of the study region to extract the most important contributor of the $\mathrm{R}_{\mathrm{NDVI} \text {-SPEI }}$ and $\mathrm{R}_{\mathrm{NDVI} \text {-scPDSI }}$ temporal dynamics based on the spearman partial correlation coefficient. To evaluate the robustness of the attribution analysis based on partial regression models, we also used Lindeman, Merenda and Gold (lmg) relative importance algorithm ${ }^{51}$ to test the relative importance of the meteorological factors and the atmospheric $\mathrm{CO}_{2}$ in explaining the variance of $\mathrm{R}_{\mathrm{NDVI}-\mathrm{SPE}}$ and $\mathrm{R}_{\mathrm{NDVI} \text {-scPDSI}}$. The algorithm was based on variance decomposition for multiple linear regression models; the relative importance of each factor was calculated based on variance of $\mathrm{R}_{\mathrm{NDVI} \text {-SPEI }}$ and $\mathrm{R}_{\mathrm{NDVI} \text {-scPDSI }}$ they explained. The relative importance was performed with the "relaimpo" package $e^{51}$ in R. This method was applied to every grid cell within the study region.

\section{Data availability}

The Advanced Very High Resolution Radiometer GIMMS-NDVI3g is available at https://ecocast.arc.nasa.gov/data/pub/gimms/3g.v0. 1-24 month time-scale of SPEIs were obtained from http://digital.csic.es/handle/10261/153475, and scPDSI from 1982 to 2014 is available at https://rda.ucar.edu/datasets/ds299.0/. Aridity index dataset is available at https://cgiarcsi.community/data/global-aridity-and-pet-database/. Atmospheric $\mathrm{CO}_{2}$ data could be available from Mauna Loa Observatory provided by the Scripps Institution of Oceanography (Scripps $\mathrm{CO}_{2}$ program). GIMMS-GPP from 1982 to 2011 is available at https://wkolby.org/data-code/. Monthly air temperature, shortwave radiation, and precipitation data are available at http://hydrology.princeton.edu/data/pgf/v2/0.5deg/ monthly/. Monthly GOSIF data were obtained from http://data.globalecology.unh.edu/ data/GOSIF/. Moderate Resolution Imaging Spectroradiometer (MODIS) based EVI and GPP datasets are available at are available from the NASA Land Processes Distributed Active Archive Center at https://lpdaac.usgs.gov. Ku-band VOD datasets are available from https://zenodo.org/record/2575599\#.XyLqfLdME0M. Essential Climate Variable (ECV) soil moisture data could be obtained from www.esa-soilmoisture-cci.org/. Irrigated area extracted using Global Map of Irrigation Areas from Food and Agriculture Organization of United Nations (FAO): http://www.fao.org/aquastat/en/geospatialinformation/global-maps-irrigated-areas/latest-version/.

\section{Code availability}

All R and Python code can be available from LW upon reasonable request.

Received: 30 November 2020; Accepted: 21 May 2021;

Published online: 18 June 2021

\section{References}

1. Novick, K. A. et al. The increasing importance of atmospheric demand for ecosystem water and carbon fluxes. Nat. Clim. Change 6, 1023-1027 (2016).

2. Ciais, P. et al. Europe-wide reduction in primary productivity caused by the heat and drought in 2003. Nature 437, 529 (2005).

3. Porporato, A., D’odorico, P., Laio, F., Ridolfi, L. \& Rodriguez-Iturbe, I Ecohydrology of water-controlled ecosystems. Adv. Water Resour. 25, 1335-1348 (2002).

4. Huang, K. et al. Enhanced peak growth of global vegetation and its key mechanisms. Nat. Ecol. Evolution 2, 1897 (2018).

5. Huang, J., Yu, H., Guan, X., Wang, G. \& Guo, R. Accelerated dryland expansion under climate change. Nat. Clim. Change 6, 166 (2016).
6. Yuan, W. et al. Increased atmospheric vapor pressure deficit reduces global vegetation growth. Sci. Adv. 5, eaax1396 (2019).

7. Jung, M. et al. Recent decline in the global land evapotranspiration trend due to limited moisture supply. Nature 467, 951 (2010).

8. Sherwood, S. \& Fu, Q. A drier future? Science 343, 737-739 (2014).

9. Lucht, W. et al. Climatic control of the high-latitude vegetation greening trend and Pinatubo effect. Science 296, 1687-1689 (2002).

10. Zhu, Z. et al. Greening of the Earth and its drivers. Nat. Clim. change 6 , 791-795 (2016)

11. Fensholt, R. et al. Greenness in semi-arid areas across the globe 1981-2007an Earth Observing Satellite based analysis of trends and drivers. Remote Sens. Environ. 121, 144-158 (2012).

12. Fernández-Martínez, M. et al. Global trends in carbon sinks and their relationships with $\mathrm{CO}_{2}$ and temperature. Nat. Clim. change 9, 73 (2019).

13. Dannenberg, M. P., Wise, E. K. \& Smith, W. K. Reduced tree growth in the semiarid United States due to asymmetric responses to intensifying precipitation extremes. Sci. Adv. 5, eaaw0667 (2019).

14. Piao, S. et al. Evidence for a weakening relationship between interannual temperature variability and northern vegetation activity. Nat. Commun. 5 , 5018 (2014).

15. Wild, M. et al. From dimming to brightening: decadal changes in solar radiation at Earth's surface. Science 308, 847-850 (2005).

16. Beer, C. et al. Terrestrial gross carbon dioxide uptake: global distribution and covariation with climate. Science 329, 834-838 (2010).

17. Forzieri, G., Alkama, R., Miralles, D. G. \& Cescatti, A. Satellites reveal contrasting responses of regional climate to the widespread greening of Earth. Science 356, 1180-1184 (2017).

18. Vicente-Serrano, S. M. et al. Response of vegetation to drought time-scales across global land biomes. Proc. Natl Acad. Sci. USA 110, 52-57 (2013).

19. Anderegg, W. R. et al. Hydraulic diversity of forests regulates ecosystem resilience during drought. Nature 561, 538 (2018).

20. Keenan, T. F. et al. Increase in forest water-use efficiency as atmospheric carbon dioxide concentrations rise. Nature 499, 324 (2013).

21. Jiao, W., Wang, L. \& McCabe, M. F. Multi-sensor remote sensing for drough characterization: current status, opportunities and a roadmap for the future. Remote Sens. Environ. 256, 112313 (2021).

22. Lobell, D. B. et al. Greater sensitivity to drought accompanies maize yield increase in the US Midwest. Science 344, 516-519 (2014).

23. Saleska, S. R., Didan, K., Huete, A. R. \& Da Rocha, H. R. Amazon forests green-up during 2005 drought. Science 318, 612-612 (2007).

24. Chen, T., Werf, G., Jeu, R., Wang, G. \& Dolman, A. A global analysis of the impact of drought on net primary productivity. Hydrol. Earth Syst. Sci. 17, 3885 (2013).

25. Nemani, R. R. et al. Climate-driven increases in global terrestrial net primary production from 1982 to 1999. Science 300, 1560-1563 (2003).

26. Kreuzwieser, J. \& Rennenberg, H. Molecular and physiological responses of trees to waterlogging stress. Plant, Cell Environ. 37, 2245-2259 (2014).

27. Buermann, W. et al. Widespread seasonal compensation effects of spring warming on northern plant productivity. Nature 562, 110 (2018).

28. Zhao, M. \& Running, S. W. Drought-induced reduction in global terrestrial net primary production from 2000 through 2009. Science 329, 940-943 (2010).

29. Anderegg, W. R. et al. Pervasive drought legacies in forest ecosystems and their implications for carbon cycle models. Science 349, 528-532 (2015).

30. Field, C. B., Barros, V., Stocker, T. F. \& Dahe, Q. Managing the Risks of Extreme Events and Disasters to Advance Climate Change Adaptation: Special Report of the Intergovernmental Panel on Climate Change. (Cambridge University Press, 2012).

31. Dai, A. Increasing drought under global warming in observations and models Nat. Clim. Change 3, 52 (2013).

32. Trenberth, K. E. et al. Global warming and changes in drought. Nat. Clim. Change 4, 17 (2013).

33. Cook, B. I., Ault, T. R. \& Smerdon, J. E. Unprecedented 21st century drought risk in the American Southwest and Central Plains. Sci. Adv. 1, e1400082 (2015).

34. Milly, P. C. \& Dunne, K. A. Potential evapotranspiration and continental drying. Nat. Clim. Change 6, 946 (2016).

35. $\mathrm{Xu}, \mathrm{C}$. et al. Increasing impacts of extreme droughts on vegetation productivity under climate change. Nat. Clim. Change 9, 948-953 (2019).

36. Konapala, G., Mishra, A. K., Wada, Y. \& Mann, M. E. Climate change will affect global water availability through compounding changes in seasonal precipitation and evaporation. Nat. Commun. 11, 1-10 (2020).

37. Peñuelas, J. et al. Shifting from a fertilization-dominated to a warmingdominated period. Nat. Ecol. Evolution 1, 1438-1445 (2017).

38. Humphrey, V. et al. Sensitivity of atmospheric $\mathrm{CO}_{2}$ growth rate to observed changes in terrestrial water storage. Nature 560, 628-631 (2018). 
39. Vicente-Serrano, S. M., Beguería, S. \& López-Moreno, J. I. A multiscalar drought index sensitive to global warming: the standardized precipitation evapotranspiration index. J. Clim. 23, 1696-1718 (2010).

40. Doughty, C. E. et al. Drought impact on forest carbon dynamics and fluxes in Amazonia. Nature 519, 78-82 (2015).

41. Schwalm, C. R. et al. Global patterns of drought recovery. Nature 548, 202 (2017).

42. Peters, W. et al. Increased water-use efficiency and reduced $\mathrm{CO}_{2}$ uptake by plants during droughts at a continental scale. Nat. Geosci. 11, 744 (2018)

43. Hugelius, G. et al. Large stocks of peatland carbon and nitrogen are vulnerable to permafrost thaw. Proc. Natl Acad. Sci. USA 117, 20438-20446 (2020).

44. Minasny, B. et al. Digital mapping of peatlands-A critical review. Earth-Sci. Rev. 196, 102870 (2019).

45. Cronk, J. K. \& Fennessy, M. S. Wetland Plants: Biology and Ecology. (CRC press, 2016).

46. Zohaib, M. \& Choi, M. Satellite-based global-scale irrigation water use and its contemporary trends. Sci. Total Environ. 714, 136719 (2020).

47. Smith, W. K. et al. Large divergence of satellite and Earth system model estimates of global terrestrial $\mathrm{CO}_{2}$ fertilization. Nat. Clim. Change 6, 306 (2016).

48. Abel, C. et al. The human-environment nexus and vegetation-rainfall sensitivity in tropical drylands. Nat. Sustain. 4, 25-32 (2020).

49. Lu, X., Wang, L. \& McCabe, M. F. Elevated $\mathrm{CO}_{2}$ as a driver of global dryland greening. Sci. Rep. 6, 20716 (2016).

50. Oliveira, P. J., Davin, E. L., Levis, S. \& Seneviratne, S. I. Vegetation-mediated impacts of trends in global radiation on land hydrology: a global sensitivity study. Glob. Change Biol. 17, 3453-3467 (2011).

51. Grömping, U. Relative importance for linear regression in R: the package relaimpo. J. Stat. Softw. 17, 1-27 (2006).

52. Moesinger, L. et al. The global long-term microwave vegetation optical depth climate archive (VODCA). Earth Syst. Sci. Data 12, 177-196 (2020).

53. Li, X. \& Xiao, J. A global, 0.05-degree product of solar-induced chlorophyll fluorescence derived from OCO-2, MODIS, and reanalysis data. Remote Sens. 11, 517 (2019).

54. Palmer, W. C. Meteorological Drought. Vol. 30 (Citeseer, 1965).

55. Abatzoglou, J. T., Dobrowski, S. Z., Parks, S. A. \& Hegewisch, K. C. TerraClimate, a high-resolution global dataset of monthly climate and climatic water balance from 1958-2015. Sci. Data 5, 170191 (2018).

56. Trabucco, A. \& Zomer, R. J. Global aridity index (global-aridity) and global potential evapo-transpiration (global-PET) geospatial database. CGIAR Consortium for Spatial Information (2009).

57. Zomer, R. J., Trabucco, A., Bossio, D. A. \& Verchot, L. V. Climate change mitigation: a spatial analysis of global land suitability for clean development mechanism afforestation and reforestation. Agriculture, Ecosyst. Environ. 126, 67-80 (2008).

58. Gruber, A., Scanlon, T., Schalie, R. V. D., Wagner, W. \& Dorigo, W. Evolution of the ESA CCI soil moisture climate data records and their underlying merging methodology. Earth Syst. Sci. Data 11, 717-739 (2019).

59. Dorigo, W. et al. ESA CCI Soil moisture for improved Earth system understanding: State-of-the art and future directions. Remote Sens. Environ. 203, 185-215 (2017).

60. Wagner, W. et al. Fusion of active and passive microwave observations to create an essential climate variable data record on soil moisture. ISPRS Annals of the Photogrammetry, Remote Sensing and Spatial Information Sciences (ISPRS Annals) 7, 315-321 (2012).

61. Harris, I., Jones, P., Osborn, T. \& Lister, D. Updated high-resolution grids of monthly climatic observations-the CRU TS3. 10 Dataset. Int. J. Climatol. 34, 623-642 (2014).

62. Sheffield, J., Goteti, G. \& Wood, E. F. Development of a 50-year highresolution global dataset of meteorological forcings for land surface modeling. J. Clim. 19, 3088-3111 (2006).

63. Tian, F. et al. Remote sensing of vegetation dynamics in drylands: Evaluating vegetation optical depth (VOD) using AVHRR NDVI and in situ green biomass data over West African Sahel. Remote Sens. Environ. 177, 265-276 (2016).

64. Reichstein, M. et al. Climate extremes and the carbon cycle. Nature 500, 287-295 (2013).
65. Frank, D. et al. Effects of climate extremes on the terrestrial carbon cycle: concepts, processes and potential future impacts. Glob. Change Biol. 21, 2861-2880 (2015)

66. Goetz, S. J., Bunn, A. G., Fiske, G. J. \& Houghton, R. A. Satellite-observed photosynthetic trends across boreal North America associated with climate and fire disturbance. Proc. Natl Acad. Sci. USA 102, 13521-13525 (2005).

67. Wu, D. et al. Time-lag effects of global vegetation responses to climate change Glob. Change Biol. 21, 3520-3531 (2015).

68. Tei, S. \& Sugimoto, A. Time lag and negative responses of forest greenness and tree growth to warming over circumboreal forests. Glob. Change Biol. 24, 4225-4237 (2018).

69. Wen, Y. et al. Cumulative effects of climatic factors on terrestrial vegetation growth. J. Geophys. Res.: Biogeosciences 124, 789-806 (2019).

70. McKee, T. B., Doesken, N. J. \& Kleist, J. in Proceedings of the 8th Conference on Applied Climatology. 179-183 (American Meteorological Society Boston, MA).

71. Jiao, W., Tian, C., Chang, Q., Novick, K. A. \& Wang, L. A new multi-sensor integrated index for drought monitoring. Agric. For. Meteorol. 268, 74-85 (2019).

\section{Acknowledgements}

We acknowledge support from Division of Earth Sciences of National Science Foundation (EAR-1554894) and from the Agriculture and Food Research Initiative program (201767013-26191) of the United States Department of Agriculture National Institute of Food and Agriculture. W.K.S. acknowledges funding from NASA Terrestrial Ecosystems Grant 80NSSC19M0103.

\section{Author contributions}

W.J. and L.W. conceptualized the main research questions. W.J., Q.C., and H.W. collected data and performed the data analyses. W.J. and L.W. wrote the first draft. W.K.S. contributed additional data and revised the manuscript. P.D. contributed ideas and revised the manuscript. All the authors contributed ideas and edited the manuscript.

\section{Competing interests}

The authors declare no competing interests.

\section{Additional information}

Supplementary information The online version contains supplementary material available at https://doi.org/10.1038/s41467-021-24016-9.

Correspondence and requests for materials should be addressed to L.W.

Peer review information Nature Communications thanks the anonymous reviewers for their contribution to the peer review of this work.

Reprints and permission information is available at http://www.nature.com/reprints

Publisher's note Springer Nature remains neutral with regard to jurisdictional claims in published maps and institutional affiliations.

Open Access This article is licensed under a Creative Commons Attribution 4.0 International License, which permits use, sharing, adaptation, distribution and reproduction in any medium or format, as long as you give appropriate credit to the original author(s) and the source, provide a link to the Creative Commons license, and indicate if changes were made. The images or other third party material in this article are included in the article's Creative Commons license, unless indicated otherwise in a credit line to the material. If material is not included in the article's Creative Commons license and your intended use is not permitted by statutory regulation or exceeds the permitted use, you will need to obtain permission directly from the copyright holder. To view a copy of this license, visit http://creativecommons.org/ licenses/by/4.0/

(C) The Author(s) 2021 